\title{
Pedagogía de la Muerte y Proceso de Duelo. Cuentos como Recurso Didáctico
}

\section{Pedagogy of Death and Mourning Process. Stories as Didactic Resource}

\author{
Ernesto Colomo Magaña * \\ Universidad Internacional de Valencia
}

\begin{abstract}
Pese a que la muerte y las situaciones de duelo son una realidad inevitable por las que todos pasamos en algún momento de nuestras vidas, aún no hemos conseguido abordarlos plenamente desde el punto de vista pedagógico. Una educación completa requiere el tratamiento de todos aquellos temas que afecten a nuestra condición de seres humanos, siendo nuestra finitud un ámbito sobre el que profundizar para un completo crecimiento y desarrollo a nivel personal y social. En los últimos tiempos se están consolidando líneas de investigación en torno a este fenómeno con el propósito de introducirlo y abordarlo desde los diferentes contextos educativos. Este artículo pretende reflexionar sobre el tema de la muerte y la superación positiva de las situaciones de duelo, aportando una propuesta para la Pedagogía de la Muerte en la que se utilicen los cuentos como recurso didáctico. El uso de los cuentos como material educativo se fundamenta en sus posibilidades para la reflexión, el aumento de nuestra confianza y la comprensión del fenómeno de la muerte como un proceso más de la vida. Para ello planteamos una propuesta didáctica que recoge cuentos que tratan sobre diferentes aspectos de esta temática, acompañados de material didáctico para profundizar y enriquecer la comprensión y el aprendizaje. Finalmente, en las conclusiones destacamos la importancia de introducir la Pedagogía de la Muerte en la educación, además de subrayar las posibilidades de los cuentos como recurso pedagógico para abordarlo.
\end{abstract}

Descriptores: Pedagogía de la muerte, Situaciones de duelo, Cuentos, Propuesta pedagógica, Recurso didáctico.

\begin{abstract}
Although death and bereavement situations are an unavoidable reality that we all encounter at some point in our lives, we have not yet managed to fully address them from a pedagogical point of view. A complete education requires treatment of all the matters that affect our condition as human beings; our finite state is an area we must deepen to achieve comprehensive growth and development on both a personal and social level. Recent studies strive to investigate this phenomenon in order to approach it from different educational contexts. This article aims to reflect upon the theme of death and the positive overcoming of situations of mourning, providing a proposal for the Education of Death in which stories are used as a teaching resource. The use of stories as educational material is based on their potential for reflection, increasing our confidence and understanding of the phenomenon of death as another process of life. For this we propose a didactic approach that collects stories that deal with different aspects of this theme, accompanied by teaching materials to deepen and enrich understanding and learning. Finally, the conclusions highlight the importance of introducing the Pedagogy of Death in education, while stressing the possibilities of storytelling as an educational resource to address it.
\end{abstract}

Keywords: Pedagogy of death, Mourning situations, Stories, Pedagogical proposal, Didactic resource.

*Contacto: ernesto.c.magana@hotmail.com

ISSN: $1696-4713$

www.rinace.net/reice/
Recibido:

15 de mayo 2015

$1^{\text {a }}$ Evaluación: 13 de julio de 2015

$2^{\text {a }}$ Evaluación: 18 de septiembre 2015

Aceptado: $\quad 11$ de enero 2016 


\section{Introducción}

La muerte es algo que no debemos temer porque mientras nosotros somos, la muerte no es, y cuando la muerte es, nosotros no somos. (Antonio Machado)

Entre todas las dudas existenciales que posee el hombre, la única que ofrece una respuesta innegable es el tema de la muerte. Esta forma parte de nuestro componente vital y no podemos considerarla como un riesgo, sino como una certeza que transforma completamente nuestra vida. No obstante, hoy en día se ha convertido en un tema tabú que obviamos con el fin de no sentirnos próximos a ella, ya que sigue siendo una de las grandes preocupaciones para muchísimas personas. Desde una óptica existencial, comprendemos el grado de inquietud e incertidumbre alrededor de lo que sucede al final de la vida; sin embargo, las soluciones no suelen pasar por abordar directamente esta realidad. Y es que "aprendemos para sobrevivir a través de la cultura, las reflexiones y los pensamientos pero solemos educar pensando solo en la vida, sin considerar que morir es nuestro fin inevitable, por lo que llegamos a ella normalmente sin estar preparados" (Colomo y Oña, 2014, p. 110). Stanislav Grof (2006) argumenta que una sociedad en la que apartamos la muerte de nuestra cotidianidad, no nos prepara para nuestra defunción ni para las de las personas que nos rodean. El veto sobre este tema es uno de los problemas que nos encontramos ante las situaciones de duelo a nivel educativo. Tal como afirmaba José Luis Sampedro (2015), "en lugar de reconocer que la muerte es el coronamiento de la vida, que forma parte de ella, que es el episodio final, la bajada del telón, en vez de educarnos en esa idea, escamotean el momento y no nos habitúan a pensar que uno es mortal" (p. 75).

El fallecimiento de alguna persona de nuestro entorno es un proceso que con mucha probabilidad todos viviremos (Echeburúa y Herrán, 2007). Pese a ello, se trata de una parcela educativa poco explorada y trabajada que requiere con urgencia de nuestra atención. Por esta razón, debemos familiarizar a todas las personas con este trance. Se trata de ayudarlos a entender este proceso como algo natural a la vez que alejado de toda visión trágica y sensación de miedo. Pensamos que si las personas comprenden que todo ser humano es mortal, estaremos favoreciendo la superación positiva de las pérdidas que podamos sufrir a lo largo de nuestras vidas. De esta manera, si aceptamos la muerte como algo físico podremos valorar lo que es importante cuando alguien se marcha: el sentido que quiso dar a su vida (Savater, 1999).

Para lograr este cometido, hemos realizado una propuesta didáctica en la que trabajaremos con los cuentos como herramienta pedagógica para abordar el tema de la muerte, convirtiéndose en un medio de prevención ante posibles situaciones de duelo. Este tipo de relatos sirven como instrumento para comprender mejor la realidad, a la vez que dan respuestas y ejemplos de cómo resolver algunos de los problemas universales como el que nos concierne. Los cuentos nos deben servir para reflexionar, aumentar nuestra confianza y entender el fenómeno de la muerte como un proceso más de la vida (Selfa, Fraga y Berengué, 2015).

Partiendo de lo expuesto, este artículo tiene como objetivo general trabajar pedagógicamente la muerte y los procesos de duelo utilizando los cuentos como recurso educativo. Entre los objetivos específicos tendríamos: a) establecer propuestas y tareas a realizar por los docentes para ayudar a la superación positiva del duelo; y b) crear 
material didáctico para trabajar y reflexionar sobre los cuentos que abordan el tema de la muerte.

\section{La Muerte en el Contexto Educativo}

Como ser vivo, el hombre nace y muere siguiendo las leyes de la naturaleza. Todos los seres humanos completan antes o después este último viaje. Una travesía necesaria para el crecimiento de la raza humana que vive en un proceso de evolución constante marcado por la renovación y transformación, con ciclos de nacimientos y muertes de manera continua (Colomo y Oña, 2014).

La muerte se convierte de esta forma en un suceso único y universal (Benítez, 2014; Oviedo, Parra y Marquina, 2009). Se trata de un concepto con varios significados debido a que está influenciado por el prisma social, cultural y científico desde el que se mire (Suárez, 2011). De esta manera, el hecho y la noción de muerte está en función del contexto sociocultural donde ocurra, aunque sí podemos establecer unas características comunes/generales sobre la misma. Se trata de un fenómeno que alcanza a todas las personas y del que no se puede escapar. Morir es una realidad personal e intransferible, ya que como sostiene Savater (1999), "la deuda que todos tenemos con la muerte la debe pagar cada cual con su propia vida, no con otra" (p. 35). No obstante, la incertidumbre en cuanto a cuándo y cómo se producirá ha provocado que, tal como expone el doctor Gaona (2012), la curiosidad y reflexión sobre la muerte sea algo compartido en la historia del ser humano desde sus orígenes en todas las partes del mundo.

Solo al comprenderla estamos descubriendo el valor de nuestra existencia. "Somos nosotros quienes llevamos las riendas de nuestra vida y con nuestra forma de vivir, vamos enmarcando nuestra forma de morir" (Pacheco, 2003, p. 38). Sin embargo, el tema de la muerte es obviado dentro del ámbito pedagógico como han señalado muchos autores (Arnaiz, 2003; Colomo y Oña, 2014; Cortina, 2003; González y Herrán, 2010; Herrán y Cortina, 2006, 2009; Mèlich, 2003; Poch, 2000, 2009; Rodríguez y Goyarrola, 2012). Esta situación hace que los profesionales de la educación tengan escasa o nula formación sobre cómo tratar la muerte y los procesos de duelo a nivel pedagógico. Existe una débil presencia de estudios en ciencias humanas sobre el duelo (Suárez, 2011) pese a que es una situación de la vida que probablemente todos nosotros habremos de conocer. Por ello, pensamos que desde el ámbito educativo debemos estar formados y preparados para dar respuestas al interrogante del tema de la muerte. Por otra parte, tenemos que tener herramientas para abordar las situaciones de duelo de manera preventiva y cuándo estas se produzcan en el contexto pedagógico. En esta propuesta, nos vamos a centrar en trabajar el tema del duelo, pasando a continuación a abordar el concepto y la realidad de este proceso psicológico.

\subsection{El duelo: perspectiva pedagógica}

Son varios los autores (Echeburúa y Herrán, 2007; Gómez Sancho, 2007; Posada, 2005) que ven el duelo como la respuesta o reacción que se presenta ante la pérdida de un ser querido; por lo tanto es fundamental entenderlo como un proceso en movimiento, con cambios y múltiples posibilidades de expresión y no como un estado estático con límites rígidos. En la definición de Pacheco (2003) podemos observar las principales características del mismo: 
El duelo es una respuesta universal a una pérdida (o a una separación) a la que se enfrentan los seres humanos de todas las edades y de todas las culturas (...) Es algo personal y único y cada persona lo experimenta a su modo y manera. Sin embargo, produce reacciones humanas comunes. El duelo es una experiencia global, que afecta a la persona en su totalidad: en sus aspectos psicológicos, emotivos, mentales, sociales, fisicos y espirituales. (p. 33)

Por lo tanto, se trata de un proceso psicológico complejo en el que se debe enfrentar el dolor de la ausencia, trabajando para reformular los vínculos afectivos con el fallecido con el fin de seguir viviendo tras asimilar la pérdida. Thomas (1991) sostiene que un duelo superado positivamente ayuda a madurar a las personas y estimula sus facultades creadoras; por el contrario, no hay nada más perjudicial que un duelo frustrado o no expresado adecuadamente. Echeburúa y Herrán (2007) sostienen que la pérdida de un ser querido puede ser el factor más estresante en la vida de una persona. Por ello, desde el ámbito pedagógico, los profesionales de la educación debemos abordar el tema de la muerte y las situaciones de duelo. Herrán y Cortina (2009) afirman que desde nuestro liderazgo, comportamiento, actitudes, disponibilidad, nuestra capacidad de influencia sobre él y porque nos acepta, se le puede transmitir al educando la idea de que queremos y podemos compartir con él su dolor y su tristeza. Nuestro fin es ayudar en la superación positiva del duelo. Para ello, abordaremos las cuatro tareas propuestas por Worden (1997):

- Reconocer la realidad de la pérdida, entendiendo que la persona no volverá. Puede llevar tiempo porque implica una aceptación tanto intelectual como emocional. Asumir la mortalidad de todo ser humano, incluida la propia, desde un proceso de introspección, favorece un mayor grado de aceptación en el proceso de duelo.

- Trabajar las emociones y el dolor de la pérdida, intentando evitar síntomas u otras formas de conductas disfuncional. Se trata, como señalan varios autores (Echeburúa, 2004; Echeburúa, Corral y Amor, 2001), de interrumpir las conductas que mantienen el vínculo con el pasado y las situaciones que ya son irreversibles. Si no se realiza adecuadamente, puede ser necesaria una intervención posterior en un momento dónde ya es complejo volver atrás para ocuparse del dolor que se ha tratado de evitar. Por ello es muy interesante la labor de prevención o formación previa ante las posibles situaciones de duelo que podamos vivir, desarrollando las mismas desde el contex to educativo para que el tema de la muerte forme parte de la realidad de los educandos.

- Adaptarse a un medio en el que el fallecido está ausente, lo que conlleva asumir roles distintos en un nuevo medio sin esa persona. Las circunstancias y el contexto de cada pérdida hacen que no exista un esquema único de cómo una persona manifiesta y afronta su duelo. Además, los lazos emocionales con el difunto hacen que existan variaciones en una misma persona en las distintas pérdidas que sufra. Todos estos aspectos marcan y definen esta realidad, de manera que cada proceso de duelo será único y diferente en cierto modo, por lo que no existe un patrón único de respuesta; más bien consiste en mantenerse a disposición del alumno, ofreciéndole el apoyo necesario para solventar las necesidades que manifieste. 
- Recolocar emocionalmente al fallecido y seguir viviendo, ya que para muchas personas su vida se detiene cuando se produce la pérdida. Se trata de resituar la imagen del fallecido en la biografía del que ha sufrido la pérdida. Los profesionales que trabajen con personas en situación de duelo deben ayudar a que los sujetos encuentren un lugar para el fallecido en su vida emocional y así puedan continuar con sus vidas sin él. No se trata de olvidar, sino de reubicar emocionalmente a las personas que ya no están.

Para abordar estas cuatro tareas, usaremos como herramienta pedagógica los cuentos, un potente recurso didáctico que por sus características y beneficios puede reportarnos resultados positivos en dicha labor. Seguidamente, profundizaremos sobre sus posibilidades dentro de nuestro estudio.

\subsection{Los cuentos como recurso didáctico}

Lo cierto es que en todas las comunidades del mundo y en todas las épocas se han narrado y contado historias, siendo un arte tan antiguo como la humanidad (Padovani, 1999). Y es que los cuentos sirven como medio para comprender mejor el contexto y la vida. Jiménez (2001) los define como "una narración breve, de trama sencilla, caracterizada por una fuerte concentración de la acción, del tiempo y del espacio. Es un relato no muy extenso que conlleva una sucesión de motivos y episodios que aparecen en todas las culturas" (p. 83). Como ocurre con otros elementos culturales, los relatos son una herramienta representativa de la realidad y un instrumento fundamental para contactar significativamente con la sociedad. Bettelheim (1997) sostiene que los cuentos aportan mensajes que hacen referencia a los problemas humanos universales, convirtiéndose así en un instrumento muy relevante que favorece y estimula el desarrollo y aprendizajes de los educandos.

Son varios los autores que han investigado el cuento desde la perspectiva educativa con el fin de corroborar su potencial en el proceso de enseñanza-aprendizaje. Por un lado, el trabajo de Cashdan (2000) cuyas conclusiones quedan recogidas en la tesis de Salmerón (2004), sostiene que los cuentos constituyen un elemento imprescindible para el desarrollo óptimo de los jóvenes, ya que los problemas que aparecen y las resoluciones de los mismos, se convierten en ejemplos a la hora de enfrentarse a los problemas propios de la vida real, manteniendo así la visión de Bettelheim. Por otra parte, autores como Bruner (1999) o McEwan y Egan (1998) nos dicen que gracias a la narrativa, somos capaces de organizar y dar a conocer tanto nuestros hábitos como el de los otros, ya que en los cuentos se van a presentar unas acciones, sucesos o problemas que han de solucionarse, temores, sueños, habilidades sociales e incluso emociones, que siempre pertenecen a un sujeto concreto o al contexto en que se enmarca la narración. Siguiendo esta misma línea, se establecerían dos de las finalidades que tienen los cuentos (Quintana, 2005):

- Proyectar en la lectura la propia vida, ansias, miedos o incluso los propios ideales, y encontrando en las lecturas experiencias ajenas con las que se puedan identificar y les sirvan de recomendación y consejo personal.

- Crecer descubriendo nuevos mundos y nuevos conocimientos que ayuden a los sujetos a comprender su propia cultura y el mundo.

De este modo, nos encontramos ante un medio con posibilidades infinitas para la educación si son bien trabajados, debiendo distinguir entre educar "con”, "en” y "ante" 
los cuentos. Educar “con” los cuentos sería utilizarlos como instrumento didáctico o como lección, pudiendo también usarlos como parte de un proceso creativo en el que los alumnos escriban sus propios relatos. En cuanto a educar "en" los cuentos, sería enseñar a los educandos a realizar lecturas más críticas de sus contenidos, de manera que sepan detectar los mensajes y enseñanzas trasladadas a nivel educativo, cultural, económico, social o ideológico. Por último, educar “ante” los cuentos conllevaría una capacidad selectiva a la hora de elegir los cuentos que lean.

Todas estas posibilidades nos llevan a pensar que los relatos pueden ser un instrumento pedagógico provechoso para trabajar de manera preventiva el tema de la muerte y ayudarnos en la realización de un proceso de duelo normalizado (Selfa, Fraga y Berengué, 2015). Con ellos otorgamos a los educandos escenarios imaginarios que difícilmente podrían concebir por sí mismos, sirviéndoles para transformar los contenidos de su propio inconsciente sobre el tema de la muerte (Gillig, 1997). Gracias a los mismos podemos acceder a la representación de la realidad de este fenómeno ofrecido y compartido por una sociedad determinada en función de su contexto sociocultural. Colomo y Oña (2014) sostienen que

\footnotetext{
Mediante estos contenidos podemos colaborar en que los educandos se adapten a la realidad, aprendiendo a superar los temores, limitaciones que tengan y a crecer interiormente para potenciar su desarrollo como seres humanos completos que son conscientes de su finitud. (p. 111)
}

Hay que tener en cuenta que los actos educativos que desarrollaremos deberán estar alejados de visiones autoritarias, coercitivas o impuestas, centrándose estos en los sentimientos ante un hecho ineludible que tendremos que afrontar, tarde o temprano, por nuestra condición de seres vivos. Los relatos deben servirnos para reflexionar sobre la experiencia vivida, permitiéndonos reconstruir nuestro mundo interno positivamente y aumentar nuestra confianza personal a través de la identificación con los protagonistas de las historias.

\section{Propuestas Didácticas para el Tratamiento de la Muerte y el Duelo a través de los Cuentos}

Nuestra propuesta didáctica consistirá en abordar el tema de la muerte, desde el contexto educativo, como forma de preparar a los educandos ante posibles situaciones de duelo y/o la superación positiva de estas cuando se produzcan, utilizando los cuentos como herramienta pedagógica. Pensamos que dichos relatos pueden ser un instrumento educativo positivo puesto que el aula, como defiende Colomo (2015), es el lugar ideal de ensayo para la vida, siendo la muerte un tema ineludible de la misma. Pueden usarse en diferentes momentos y desde diferentes enfoques, ya sea trabajándolos en un taller, un seminario, etc., convirtiéndose así en un complemento didáctico para los profesionales de la educación.

Se trataría, por tanto, de una formación preventiva con respecto a todo el grupo/clase. Dichas actividades estarán dirigidas a alumnos a partir de los niveles de secundaria y bachillerato por las características del tema. También incluiremos esta propuesta para la formación de los futuros docentes (a nivel universitario) por la importancia de prepararlos en este ámbito de cara a poder afrontarlo con recursos y preparación en el contexto escolar. 
Las temáticas de los cuentos con los que trabajaremos el fenómeno del duelo estarán centradas en los siguientes hechos cotidianos expuestos por Herrán y Cortina (2006):

- La mortalidad de todo ser humano.

- La omnipresencia de la muerte.

- La presencia de aquellos que murieron.

La muestra de cuentos que utilizaremos estará compuesta por una selección centrada en dichas temáticas. Para su elección realizamos una revisión bibliográfica en la que buscamos relatos cuyo contenido ilustrara esta realidad. Incluimos la creación propia de un texto para uno de los temas debido a que la búsqueda no había satisfecho nuestras expectativas. La elección de los cuentos y el material de reflexión creado para trabajarlos se validó mediante el criterio de juicios de expertos por parte de un grupo de profesores pertenecientes a las Universidades de Sevilla y Málaga (miembros de los departamentos de Teoría e Historia de la Educación y Pedagogía Social de ambas universidades). Los criterios establecidos fueron la concordancia del relato con la temática y la adecuación pedagógica del material didáctico para los educandos de los distintos niveles contemplados.

Con los cuentos plantearemos pequeñas historias ficticias en las que se darán situaciones posibles en torno al fenómeno de la muerte. Así, los educandos podrán analizar los pros y los contras de los comportamientos y respuestas que los personajes de las fábulas dan ante los sucesos acaecidos. De esta manera, situamos a nuestros discentes ante situaciones que les hagan replantearse sus actitudes y conocimientos acerca del duelo. La idea es que complementen lo que ya conocen con la nueva información y aprendizajes que desarrollen, preparándolos así ante posibles escenarios en sus vidas donde se haga presente la muerte, a la par que le dotemos de herramientas para poder afrontar situaciones de duelo.

Para lograr éstos propósitos trabajaremos utilizando una metodología colaborativa. Las historias serán narradas para todo el grupo/clase, de manera que hagamos partícipe de esta realidad a todos nuestros alumnos. Selfa, Fraga y Berengué (2015) sostienen que leer y dialogar acerca de lo leído en textos literarios es un poderoso método para hacer frente a acontecimientos significativos, como ocurre con nuestra temática de estudio. De este modo, al narrar los cuentos de cada una de las temáticas que abordaremos, se realiza una reflexión individual de la historia planteada para realizar posteriormente una puesta en común de las distintas visiones y aprendizajes obtenidos, con su correspondiente discusión. El motivo de utilizar esta metodología es que, como señala Carretero (1993), "el alumno aprende de forma más eficaz cuando lo hace en un contexto de colaboración e intercambio con sus compañeros, como son las discusiones de grupo y el poder de la argumentación en la discrepancia entre alumnos que poseen distintos grados de conocimiento sobre un tema" (p. 26). Con la discusión pretendemos que el educando comprenda el significado y la situación narrada, obteniendo un aprendizaje válido para su vida en el que no ha imitado explícitamente un comportamiento, ni se ha dejado guiar, ni lo ha hecho porque lo refuercen, sino que ha aprendido por un proceso de construcción mental fundamentado en la lógica y el pensamiento (Colomo, 2014).

En toda esta labor es muy relevante el papel que desarrollemos como docentes. Se trata de que los profesionales de la educación acompañemos a los alumnos en estos difíciles momentos, actuando de manera que les ofrezcamos nuestra experiencia y formación para 
compartir dicha situación trágica. Además de esta propuesta de prevención, en los casos en que se produzca un caso de duelo debemos realizar una serie de actuaciones (Herrán y Cortina, 2009) que permitan:

- Abrir canales para la expresión posible del niño, respetando cualquier tipo de manifestación (incluida la no expresión) que pueda tener lugar.

- Ofrecer la contención y el apoyo necesario permitiendo que haga su propio recorrido aunque no responda a ningún esquema preestablecido ni a nuestras expectativas. Echeburúa y Herrán (2007) sostienen que cada persona precisa de un tiempo y una forma concreta de sobrellevar su duelo que no es necesariamente intercambiable con la de otras personas.

- Mantenerse disponible y permitir que se apoye en nosotros en cualquier momento, para que reemprenda la escalada. Nuestra oferta de ayuda no debe limitarse solo al principio sino que debería mantenerse en el tiempo, ya que cada persona tiene 'un tiempo' para la elaboración del duelo y para 'enterarse' de lo que sucede

- Seguir desde atrás, es decir, 'quitarnos de en medio' para que sean sus necesidades las que se atiendan en primer término y no las nuestras, favoreciendo su autonomía.

A continuación presentamos la propuesta didáctica, desarrollada con 88 alumnos matriculados en el Máster Universitario en Formación del Profesorado en Educación Secundaria Obligatoria, Bachillerato, Formación Profesional y Enseñanza de Idiomas de la asignatura «Educación emocional y habilidades sociales», en la Universidad Internacional de Valencia (VIU) durante el curso 2014/2015. El fin es contribuir a la comprensión y aprendizaje entorno al fenómeno del duelo utilizando los cuentos dentro del área educativa de la Pedagogía de la Muerte. Partiendo de esta realidad, la labor del educador se basará en profundizar sobre las temáticas escogidas durante tres sesiones de seminario (una por cada cuento a trabajar).

\subsection{Cuento I: sobre la mortalidad de todo ser humano}

Este relato se ha creado para profundizar en la temática de la mortalidad de todo ser humano. Hemos escogido el miedo a morir como núcleo sobre el cuál construir la historia. El motivo es que pese al deseo del hombre de poder escapar de su fúnebre destino, la muerte es una realidad personal e intransferible que cada uno debe pagar con su propia vida. La etapa de referencia será a partir de Educación Secundaria en adelante a la hora de trabajarlo a nivel escolar. Entre los objetivos que persigue este relato se encuentran: aceptar nuestra condición mortal como seres vivos; prepararnos psicológica, emocional, social y culturalmente para un final irremediable; y comprender las pérdidas y el duelo como parte inherente de nuestra condición humana.

«Hace mucho tiempo, en un lugar lejano, vivió un rey al que la muerte fue a visitar. Con hábito oscuro y guadaña en ristre, el segador de almas vino a llevarse la del monarca. Pero su majestad, por miedo a vagar por siempre en la eterna noche oscura, ofreció un trato al ángel exterminador.

- Cada vez que mi hora se acerque, uno de mis súbditos entregará su vida como pago compensatorio por la mía.

La muerte accedió, dejando en su conciencia y sus manos esta decisión. Ese mismo día, el rey reunió a todos sus súbditos y les prometió que aquellos que dieran su 
vida por él, como signo de amor a su soberano, serían recompensados en la otra vida con el paraíso. Por la contra, aquellos que no accediesen voluntariamente a este propósito, serían ejecutados por deslealtad y castigados al fuego perpetuo. De esta manera, la muerte no tardó en empezar a llevarse, uno por uno, a todos los súbditos del reino. Pasaron varios años de aquella primera visita que la muerte realizó al rey, hasta que un día esta volvió a presentarse en la sala del trono.

- ¡Qué haces aquí! -exclamó sorprendido el monarca- Teníamos un trato. Mis súbditos están muriendo por mí.

- Así ha sido. -afirmó la muerte- Nuestro pacto se ha cumplido desde entonces hasta esta misma mañana. Tu oferta te ha permitido vivir hasta que el último de los hombres de tu reino ha cruzado a la otra orilla.

- ¿Nadie queda? -temeroso, se atrevió a preguntar- ¿No hay restos de mi reino?

- Tu pueblo se ha extinguido -respondió con un hilo de voz.- No queda nadie. Negarte a tu último viaje ha supuesto el final de tu reino. Prolongar tu inevitable destino ha terminado con la vida de todos.

- Creí que otros podrían ocupar mi lugar, creía que podría esquivar tu venida -dijo el rey entre sollozos.

- La muerte es el final de todo ser vivo, sin nada que pueda evitarlo y sin poder ser sustituido por nadie -le señaló con la guadaña y sentenció.- Es un pago que cada uno debe hacer con su propia vida.

El rey bajo la cabeza y dejó escapar lágrimas por todos aquellos que había condenado a un fin prematuro por no aceptar su condición mortal. Fue necesario que toda una nación se destruyera por el egoísmo y el miedo de un hombre. El horizonte se cubría de tinieblas y la muerte, cual amiga, acariciaba los cabellos del monarca con sus manos muertas »

Ernesto Colomo Magaña, "El pago a la muerte". Relato propio para su uso didáctico en esta obra.

Para el relato "El pago a la muerte", se ha creado un material didáctico centrado en preguntas de reflexión sobre el texto y los temas que se derivan del mismo, para responder individualmente en primer lugar, y luego hacer una puesta en común de las mismas con todo el grupo/clase bajo la dirección, moderación y supervisión del docente. El fin es compartir la información para enriquecer las perspectivas y puntos de vista de los compañeros. El material constaría de las siguientes preguntas:

- ¿Es justa la elección del monarca? ¿Qué harías tú en su lugar y por qué? ¿Qué valor tiene nuestra vida respecto a la de los demás?

- Cuando el rey se da cuenta de qué por su egoísmo todo su pueblo ha fallecido, llora su decisión. En ese instante es consciente de que esas personas no volverán. ¿Qué importancia tiene para nosotros reconocer la realidad del fallecimiento de algún ser cercano?

- ¿Crees que las personas somos conscientes de nuestra condición mortal o pensamos en la muerte cómo algo que solo afecta a los demás?

- ¿Piensas que el hombre sabe de la continua presencia de la muerte? ¿Cómo crees que afecta esta realidad en su desarrollo psicológico, emocional, social y cultural?

- ¿Cómo influye saberse mortal uno mismo ante las pérdidas de nuestros seres queridos? 
- ¿Tener presente la muerte como algo real y aceptarlo puede resultar positivo a la hora de afrontar la pérdida de seres cercanos a nosotros? ¿Por qué?

- ¿Qué ocurriría si los seres humanos no murieran?

\subsection{Cuento II: sobre la omnipresencia de la muerte}

El relato de Jean Cocteau ilustra la temática de la omnipresencia de la muerte. Es una realidad que nos acecha allá dónde nos encontremos y de la cual no podemos huir. Como seres vivos estamos expuestos cada momento a perder la vida con independencia de la situación, contexto o lugar donde estemos. Desde la pedagogía, debemos favorecer la comprensión de que el fenómeno de la muerte es una realidad que nos acecha y de la cual no podemos huir. Solo al ser conscientes de su continua presencia podremos aceptarla como algo natural y aprovechar más cada momento de nuestra vida. Entre los objetivos que persigue este relato se encuentran: comprender la omnipresencia de la muerte como algo natural; favorecer el aprovechamiento del momento presente como realidad patente.

«Un joven jardinero persa dice a su príncipe:

- ¡Sálvame! Encontré a la Muerte esta mañana. Me hizo un gesto de amenaza. Esta noche, por milagro, quisiera estar en Ispahan.

El bondadoso príncipe le presta sus caballos. Por la tarde, el príncipe encuentra a la Muerte y le pregunta:

- Esta mañana ¿por qué hiciste a nuestro jardinero un gesto de amenaza?

- No fue un gesto de amenaza -le responde- sino un gesto de sorpresa. Pues lo veía lejos de Ispahan esta mañana y debo tomarlo esta noche en Ispahan »

Jean Cocteau, "El gesto de la muerte"

Para el relato "El gesto de la muerte", siguiendo la metodología ya usada en el cuento anterior, se han realizado una serie de preguntas de reflexión para responder personalmente y luego compartir las opiniones y reflexiones con el resto de compañeros. Entre las cuestiones tenemos las siguientes:

- ¿Qué opinas de la actitud del jardinero? ¿Cómo actuarías en su situación?

- ¿Piensas que se puede esquivar/huir de la muerte?

- ¿Saber que cada momento es el último nos puede llevar a aprovechar más la vida o lo contrario? ¿Por qué?

- ¿Piensas que es la muerte la que hace la vida más intensa, más real y que te hace crear/construir cosas?

- Son varios los autores (Colomo y Oña, 2014; Gaona, 2012; Savater, 1997) que sostienen la idea de que hay que vivir como si fueras a morir. ¿Qué cambios realizarías en tu vida si adoptarás estas premisas?

\subsection{Cuento III: sobre la presencia de aquellos que murieron}

En la mágica obra de Antoine de Saint-Exupéry, el principito trata de preparar a su amigo para el momento de su partida. Intenta que el aviador pueda reubicar sus emociones y aceptar su marcha, con el fin de lograr una adaptación a la realidad sin el fallecido. De este modo, la presencia del principito permanece viva a través del recuerdo y la contemplación de las estrellas. Entre los objetivos que persigue este relato se 
encuentran: utilizar los recuerdos como nexos de unión con los que perecieron; reubicar emocionalmente a las personas que murieron; adaptarse a una nueva realidad sin el fallecido.

«Cuando mires el cielo, por la noche, como yo habitaré en una de ellas, como yo reiré en una de ellas, será para ti como si todas las estrellas rieran. ¡Tendrás estrellas que saben reír! Y cuando te hayas consolado (uno siempre se consuela) estarás contento de haberme conocido. Siempre serás mi amigo. Tendrás ganas de reír conmigo. Y a veces abrirás tu ventana, así... por gusto. Y tus amigos se asombrarán al verte reír mirando al cielo. Entonces les dirás: "Sí, las estrellas siempre me hacen reír", y te creerán loco [...]

Solo hubo un relámpago amarillo cerca de su tobillo. Quedó inmóvil un instante. No gritó. Cayó suavemente, como cae un árbol. En la arena, ni siquiera hizo ruido $[\cdots]$

Aquí fue donde el principito apareció en la Tierra, y después desapareció. Si llegan a pasar por allí, les ruego: no se apresuren; esperen un momento, exactamente debajo de la estrella. Si entonces un niño se les acerca, si ríe, si tiene cabellos de oro, si no responde cuando se le pregunta, adivinarán quién es. ¡Entonces sean amables! No me dejen tan triste. Escríbanme enseguida, díganme que el principito ha vuelto...»

Antoine de Saint-Exupéry, "El principito".

Para el fragmento de la obra "El principito", hemos planteado unas cuestiones de reflexión sobre el texto para trabajarlos primero a nivel individual y después realizar una puesta en común de las distintas interpretaciones y aprendizajes obtenidos bajo la dirección del profesor. Entre las preguntas planteadas estarían:

- ¿Qué te parece la visión de las estrellas cómo forma de recordar al principito tras su marcha?

- ¿Crees que a través de fijar esos recuerdos podemos afrontar mejor la pérdida?

- ¿Qué situaciones o cosas te recuerdan a los que partieron de esta vida?

- ¿Cómo reaccionas ante dichos estímulos?

- ¿Son los recuerdos un mecanismo positivo para reubicar emocionalmente al fallecido y adaptarnos a un medio en el que ya no está?

- ¿Cómo te gustaría mantener latente la presencia de aquellos que murieron?

\section{Conclusión}

Tras la realización de las sesiones de seminario con los alumnos que participaron en las mismas, destacamos el acuerdo común que se alcanzó sobre la importancia de una "formación específica" en el ámbito de conocimiento de la pedagogía de la muerte. El debate refrendó la falta de conocimiento y herramientas por parte de los docentes para actuar ante un tema tan relevante a nivel educativo, ya que la muerte forma parte de la vida y es una realidad que no puede quedar al margen del contexto pedagógico. Los participantes reconocían que a nivel formativo, no se puede educar en aquellos contenidos que no se dominan. Como docentes, tenemos la obligación de subsanar y cubrir las lagunas formativas respecto a la temática del duelo, tanto a nivel teórico (necesidad de conocer las principales consignas y factores a aplicar), como práctico 
(diseño y puesta en marcha de recursos y actividades para trabajar estos casos con diferentes propuestas y metodologías). Pensamos que las Ciencias de la Educación pueden aportar sus conocimientos, instrumentos y posibilidades al tema del duelo con el propósito de ayudar y enseñar a los educandos que la vida es una realidad finita. De esta manera, no solo les ayudamos a aprender el arte de vivir (Esteve, 2010) sino que también los preparamos para esa despedida de la vida, para el arte de morir (Colomo y Oña, 2014).

Partiendo de esta idea, hemos trabajado sobre esta realidad con el deseo de que los educandos pudiesen replantearse sus actitudes y conocimientos acerca del fenómeno de la muerte y las situaciones de duelo. Los alumnos interiorizaron una serie de consignas y factores a considerar para trabajar las pérdidas tanto de manera preventiva como cuando esta se produzca en sus aulas. El fin era aportar material y recursos que sirvan para lograr la comprensión de dichas circunstancias como hechos ineludibles que forman parte de nuestra vida. Un propósito que hemos tratado de alcanzar mediante el uso didáctico de los cuentos, ya que como elemento cultural, trasladan la visión que sobre la muerte existe en nuestra sociedad de manera implícita; y además, nos la comunica en forma de mensajes cargados de emociones. Entre los resultados, destaca la buena aceptación de este recurso educativo y las posibilidades del mismo para trabajar en el control y gestión emocional ante las situaciones de duelo aprendiendo de manera preventiva mediante los ejemplos de los protagonistas, siguiendo la teoría del aprendizaje social (Bandura, 1982).

Las visiones trasladas en los relatos van a influir en las personas que las reciban, por lo que pensamos que esta propuesta es viable y ha de ser tenida en cuenta por los beneficios que puede reportar. Son auténticos vehículos educativos que llegan a influir en las formas de pensar, sentir y actuar de la sociedad, favoreciendo la creación de situaciones de aprendizaje y la comprensión sobre nuestra finitud como seres vivos a partir del debate y la reflexión, aspecto que conseguimos con la realización de las preguntas que conformaron el material didáctico. Por tanto, pueden convertirse en una herramienta con un potencial muy elevado debido a las múltiples ventajas y posibilidades que ofrece. Los cuentos pueden dar lugar a debates y puesta en común de lo aprendido entre los participantes de la actividad, lo que enriquecería su conocimiento sobre esta situación y nos daría recursos y herramientas para poder afrontar una situación inevitable que todos viviremos algún día. Los relatos nos sirven como material didáctico auxiliar o complementario para trabajar en el aula; como un medio de análisis crítico, reflexión y debate sobre la realidad de nuestra condición mortal; y como un elemento potenciador de la creatividad y de la expresión de la propia visión del ser humano sobre la muerte.

El fin es ayudar a los educandos a reconocer la finitud del ser humano debido a los beneficios que esta acción puede reportar para la superación positiva de futuras situaciones de duelo, por lo que consideramos que los resultados han sido positivos y satisfactorios. La aceptación de la muerte que proponemos desde nuestra perspectiva pedagógica suele provocar una transformación en nuestra escala de valores y personalidad (Atwater, 1988), volviéndonos personas más interesadas en las cuestiones no materiales y/o espirituales, así como reforzando las relaciones personales y nuestra entrega a los demás. La muerte nos sirve como medio para reflexionar y dar una mayor importancia a la vida y a lo que hacemos en ella (Colomo y Domínguez, 2015). El doctor Gaona (2012) afirma que "hay un mayor aprecio de las cosas pequeñas y de la vida en 
general que se torna preciosa, viven el momento con mayor intensidad, disfrutan más, es decir, trascienden sus egos y crecen espiritualmente" (p. 96).

Krishnamurti (1995) sostiene que "vivir cada día muriendo es estar en verdadero contacto con la vida" (p. 15), haciéndose preciso entender que es la existencia de la muerte, lo que da mayor valor a la vida y a los actos que hagamos durante la misma. "Porque todos nosotros, tarde o temprano, vamos a morir y solo quien acepta eso está preparado para la vida" (Coelho, 2006, p. 164). Lo verdaderamente importante y que debemos trasladar a nuestros educandos no es la incertidumbre de si hay vida después de la muerte; lo fundamental es valorar si hay vida antes de la muerte, si cada ser humano ha vivido más intensamente, de forma más real y buscando la plenitud y felicidad durante sus días.

\section{Referencias}

Arnaiz, V. (2003). Pensar, hablar de la muerte y comprometerse con la vida. Aula de Innovación Educativa, 122, 37-38.

Atwater, P.M.H. (1988). Coming back to life: The after-effects of the near-death experience. Nueva York: Dodd-Mead.

Bandura, A. (1982). Teoría del aprendizaje social. Madrid: Espasa Calpe.

Benítez, J.J. (2014). Estoy bien. Barcelona: Planeta.

Bettelheim, B. (1997). Psicoanálisis de los cuentos de hadas. Barcelona: Crítica.

Bruner, J. (1999). La educación, puerta de la cultura. Madrid: Visor.

Carretero, M. (1993). Constructivismo y educación. Zaragoza: Edelvives.

Cashdan, S. (2000). La bruja debe morir. De qué modo los cuentos de hadas influyen en los niños. Madrid: Debate.

Cocteau, J. (2008). El gesto de la muerte. En J.L. Borges (Coord.), Antología de la literatura fantástica (pp. 77-89). Barcelona: Edhasa.

Coelho, P. (2006). Como el río que fluye. Barcelona: Planeta.

Colomo, E. (2014). Análisis pedagógico de los valores presentes en las letras de las canciones (20052011). Tesis Doctoral. Málaga: Spicum.

Colomo, E. (2015). Diversidad cultural y educación. Learning \& Pedagogics, 1, 12-19.

Colomo, E. y De Oña, J.M. (2014). Pedagogía de la muerte. Las canciones como recurso didáctico. REICE. Revista Iberoamericana sobre Calidad, Eficacia y Cambio en Educación, 12(3), 109-121.

Colomo, E. y Domínguez, R. (2015). Definiendo identidades: el “canciograma” como herramienta metodológica de autoconocimiento. REICE. Revista Iberoamericana sobre Calidad, Eficacia y Cambio en Educación, 13(2), 131-146.

Cortina, M. (2003). Educar teniendo en cuenta la muerte. Aula de Innovación Educativa, 122, 5258.

Echeburúa, E. (2004). Superar un trauma: el tratamiento de las víctimas de sucesos violentos. Madrid: Pirámide.

Echeburúa, E. y Herrán, A. (2007). ¿Cuándo el duelo es patológico y cómo hay que tratarlo? Análisis y Modificación de Conducta, 33(147), 31-50. 
Echeburúa, E., Corral, P. y Amor, P.J. (2001). Estrategias de afrontamiento ante los sentimientos de culpa. Análisis y Modificación de Conducta, 27, 905-929.

Esteve, J.M. (2010). Educar: un compromiso con la memoria. Barcelona: Octaedro.

Gaona, J.M. (2012). ¿Son las experiencias cercanas a la muerte (ECM) la base empírica que demuestra la existencia del alma? Journal of Transpersonal Research, 4(2), 72-108.

Gillig, J.M. (1997). El cuento en pedagogía y en reeducación. México: Fondo de Cultura Económico.

Gómez Sancho, M. (2007). La pérdida de un ser querido: el duelo y el luto. Madrid: Aron.

González, I. y Herrán, A. (2010). Introducción metodológica a la muerte y los miedos en Educación Infantil. Tendencias Pedagógicas, 15, 124-149.

Grof, S. (2006). El viaje definitivo. Madrid: Liebre de marzo.

Herrán, A. y Cortina, M. (2006). La muerte y su didáctica. Manual para educación infantil, primaria y secundaria. Madrid: Editorial Universitas.

Herrán, A. y Cortina, M. (2007). Introducción a una pedagogía de la muerte. Educación y Futuro, 17, 131-148.

Herrán, A. y Cortina, M. (2009). La muerte y su enseñanza. Diálogo Filosófico, 75, 499-516.

Jiménez, R. (Dir.) (2001). Cuéntame: el cuento y la narración en educación infantil y primaria. Madrid: Universidad Nacional de Educación a Distancia.

Krishnamurti, J. (1995). El libro de la vida. Madrid: Edaf.

McEwan, H. y Egan, K. (1998). La narrativa de la enseñanza, el aprendizaje y la investigación. Buenos Aires: Amorrortu.

Mèlich, J.C. (2003). Por una pedagogía de la finitud. Aula de Innovación Educativa, 122, 39-40.

Oviedo, S.J., Parra, F.M. y Marquina, M. (2009). La muerte y el duelo. Enfermería Global: Revista Cuatrimestral de Enfermería, 15, 11-19.

Pacheco, G. (2003). Perspectiva antropológica y psicosocial de la muerte y el duelo. Cultura de los Cuidados, 14, 27-43.

Padovani, A. (1999). Contar cuentos: desde la práctica hacia la teoría. Barcelona: Paidós.

Poch, C. (2000). De la vida y la muerte: reflexiones y propuestas para educadores y padres. Barcelona: Claret.

Poch, C. (2009). ¿Por qué es necesaria una pedagogía de la muerte? Cuadernos de Pedagogía, 388, 52-53.

Posada, R.S. (2005). El manejo del duelo. Una propuesta para un nuevo proceso. Bogotá: Norma.

Quintana, J. (2005). La animación lectora en el aula. Madrid: CCS.

Rodríguez, P. y Gorrayola, F. (2012). Propuestas didácticas para una pedagogía de la muerte desde la creatividad artística. REICE. Revista Iberoamericana sobre Calidad, Eficacia y Cambio en Educación, 1O(2), 86-96.

Saint-Exupéry, A. (2003). El principito. Barcelona: Salamandra.

Salmerón, P. (2004). Transmisión de valores a través de los cuentos clásicos infantiles. Tesis doctoral. Granada: Editorial de la Universidad de Granada.

Sampedro, J.L. (2015). La vida perenne. Barcelona: Plaza \& Janés.

Savater, F. (1999). Las preguntas de la vida. Barcelona: Ariel. 
Selfa, M., Fraga, F.J. y Berengué, I. (2015). Leer sobre la muerte en la biblioteca de aula: una experiencia práctica de lectura en un aula de Educación Infantil. Investigaciones Sobre Lectura, 3, 83-95.

Suárez, V. (2011). Ciencia y religión: visiones y manejo emocional de la muerte y el duelo. Revista de Humanidades, 18, 49-64. doi: 10.5944/rdh.18.2011.12879

Thomas, L.V. (1991). La muerte: una lectura cultural. Barcelona: Paidós.

Worden, W. (1997). El tratamiento del duelo asesoramiento psicológico y terapia. Barcelona: Paidós. 